\title{
Knowledge of Sleep Disorders Among Physicians at a Tertiary Care Hospital in Qatar: Cross-sectional Study
}

Irfan Ul Haq ${ }^{1 *}$, MBBS, MRCP; Mansoor Ali Hameed ${ }^{1,2^{*}}$, MBBS, FRCP, FAPSR; Merlin Marry Thomas ${ }^{1,2^{*}}$, MBBS, MRCP; Khezar Shahzada Syed ${ }^{1}$, MBBS, MD; Ahmad Mohammad Mahmoud Othman ${ }^{1}$, MD; Shakeel Ahmed ${ }^{1}$, MBBS, FCPS, MRCP; Abbas Abdallah Alabbas ${ }^{1}$, MD; Mushtaq Ahmad ${ }^{1,2}$, MBBS, FRCP, FCCP

\footnotetext{
${ }^{1}$ Hamad Medical Corporation, Doha, Qatar

${ }^{2}$ Weill Cornell Medicine-Qatar, Cornell University, Doha, Qatar

*these authors contributed equally
}

\section{Corresponding Author:}

Irfan Ul Haq, MBBS, MRCP

Hamad Medical Corporation

Rayyan Road

Doha, 3050

Qatar

Phone: 97466467968

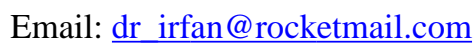

\section{Abstract}

Background: Sleep disorders constitute a major health problem because of their relatively high and rising prevalence. Several studies worldwide have analyzed health care providers' knowledge of sleep disorders.

Objective: In this study, we aimed to assess the knowledge of sleep disorders among physicians in Qatar.

Methods: A total of 250 physicians were surveyed regarding their knowledge of sleep medicine by using the validated 30-item Assessment of Sleep Knowledge in Medical Education (ASKME) Survey. The participants included residents, fellows, and consultants in medicine and allied subspecialties. A high score was defined as $\geq 60 \%$ of correctly answered questions, implying the respondent has adequate knowledge of sleep disorders.

Results: Responses were received from 158 of the 250 physicians, with a response rate of $63.2 \%$. This included responses from 34 residents, 74 clinical fellows, and 50 consultants. The overall mean score was 15.53 (SD 4.42), with the highest possible score of 30 . Only 57 of $158(36.1 \%)$ respondents were able to answer $\geq 60 \%$ of the questions correctly. No statistically significant difference was found in the scores of participants with regard to their ranks (ie, residents, fellows, or consultants) or years of medical training.

Conclusions: This study demonstrates that health care providers in Qatar have decreased awareness and knowledge about sleep medicine, which may reflect reduced emphasis on sleep disorders during medical school and training. Increasing awareness regarding sleep medicine among nonspecialist physicians will allow early detection and treatment of sleep disorders, thereby reducing the morbidity associated with these disorders.

(Interact J Med Res 2021;10(2):e25606) doi: 10.2196/25606

\section{KEYWORDS}

sleep disordered breathing; obstructive sleep apnea; sleep; physician; physician knowledge; sleep disorder; survey method; attitudes; practice

\section{Introduction}

Sleep disorders are defined as a range of sleep problems, including conditions causing hypersomnia (such as sleep apnea and narcolepsy), parasomnia (restless leg syndrome and sleepwalking), insomnia, and sleep-wake cycle disturbances.
All these sleep disorders share a common outcome-nonrestorative sleep [1]. Excessive daytime somnolence (EDS) is a consequence of sleep disorder, which can impact focus, concentration, and memory. Nonrestorative sleep and EDS are related to respiratory, cardiovascular, and neurological problems such as increased reaction time, which in turn can lead to motor vehicle and other serious accidents in 
situations where alertness is required for safety and critical decision-making [2-4]. Hence, sleep disorders are a major risk to public health. Obstructive sleep apnea (OSA), central sleep apnea, and obesity hypoventilation syndrome are treatable sleep disorders that affect a significant proportion of the population worldwide, with OSA prevalent in 3\%-5\% of middle-aged men and $2 \%-5 \%$ of women [5]. A population-based regional survey evaluating OSA in Saudi Arabia found similar data, with OSA prevalence reported at $4 \%$ and $1.8 \%$ among men and women, respectively [6].

Given the impact that sleep disorders have on the health and well-being of a significant portion of society, physicians, regardless of their specialty, will inevitably encounter patients with sleep complaints; they should, therefore, have the knowledge and awareness to diagnose sleep disorders. Unfortunately, despite the common presentation and clinical significance of these conditions, sleep disorders remain underdiagnosed or misdiagnosed and, consequently, untreated [7]. In the 2005 National Sleep Foundation's Sleep in America poll, $70 \%$ of the respondents reported that their doctor had never asked about their sleep habits or patterns [8].

As a result, sleep disorders and associated modifiable risk factors such as obesity remain unaddressed and continue to progress, leading to the worsening of disordered sleep patterns and their ensuing complications [9].

Limited studies have addressed the knowledge of sleep disorders among practicing health care practitioners in the Middle East and, to the best of our knowledge, no similar studies have been conducted on health care practitioners in the State of Qatar. Therefore, we aimed to address this gap by conducting a survey to assess the knowledge of sleep disorders among physicians working at a tertiary care center in the State of Qatar.

\section{Methods}

\section{Study Group}

We conducted a survey-based study from August 2018 to December 2018. The target population comprised postgraduate medical trainees and health care practitioners. Our study sample included residents in the Internal Medicine program and fellows in allied medical subspecialties, undertraining programs at
Hamad Medical Corporation accredited by the Accreditation Council for Graduate Medical Education-International (ACGME-I), and consultants in General Medicine and subspecialties at Hamad General and Heart Hospitals, Qatar.

\section{Survey}

We used the Assessment of Sleep Knowledge in Medical Education (ASKME) Survey, a validated 30-item questionnaire that has been designed as a standardized tool for the assessment of medical education in sleep [10]. The survey assesses five separate areas of sleep knowledge, including (1) basic sleep principles, (2) circadian sleep/wake control, (3) normal sleep architecture, (4) common sleep disorders, and (5) effects of drugs and alcohol on sleep. Possible responses to the survey items are "true," "false," and "I don't know." Participants were categorized into two groups: (1) a high score group comprising participants with correct scores $\geq 60 \%$ and (2) a low score group comprising participants with correct scores $<60 \%$, based on the cut-off pass threshold mark used in the majority of medical schools across the Gulf states.

\section{Statistical Analysis}

Continuous data are presented as means and SD, and categorical data are presented in the text and tables as absolute numbers (n) and percentages (\%). One-way analysis of variance (ANOVA) was performed for comparison between more than two groups. A $P$ value $\leq .05$ was significant. Statistical analysis was conducted using Stata Statistical Software (Release 16; StataCorp LLC).

\section{Results}

The survey was administered to 250 participants. Responses were received from 158 participants, with a response rate of $63.2 \%$. These included data collected from 34 residents in internal medicine; 74 clinical fellows training in internal medicine, cardiology, endocrinology, neurology, rheumatology, and nephrology; and 50 consultants in general medicine (Table $1)$. The majority of respondents $(121 / 158,76.6 \%)$ were male and aged above 30 years (Table 1). The participants' mean overall score was 15.53 (SD 4.42), with the highest possible score of 30. Only 57 of $158(36.1 \%)$ participants scored $\geq 60 \%$. 
Table 1. Demographics of the survey participants $(\mathrm{N}=158)$.

\begin{tabular}{|c|c|}
\hline Variable & Participants, n (\%) \\
\hline \multicolumn{2}{|l|}{ Age (years) } \\
\hline $25-30$ & $37(23.4)$ \\
\hline$>30$ & $121(76.6)$ \\
\hline \multicolumn{2}{|l|}{ Gender } \\
\hline Male & $131(82.9)$ \\
\hline Female & $27(17.1)$ \\
\hline \multicolumn{2}{|l|}{ Level of training } \\
\hline Resident & $34(21.5)$ \\
\hline Fellow & $74(46.8)$ \\
\hline Consultant & $50(31.6)$ \\
\hline \multicolumn{2}{|l|}{ Year of training } \\
\hline First year & $25(15.8)$ \\
\hline Second year & $16(10.1)$ \\
\hline Third year & $32(20.3)$ \\
\hline Fourth year & $11(7.0)$ \\
\hline More than 4 years & $74(46.8)$ \\
\hline \multicolumn{2}{|l|}{ Country of graduation } \\
\hline Pakistan & $25(15.8)$ \\
\hline Jordan & $16(10.1)$ \\
\hline Libya & $14(8.9)$ \\
\hline Syria & $12(7.6)$ \\
\hline Sudan & $12(7.6)$ \\
\hline India & $10(6.3)$ \\
\hline Egypt & $8(5.1)$ \\
\hline Qatar & $7(4.4)$ \\
\hline United Kingdom & $4(2.5)$ \\
\hline Palestine & $4(2.5)$ \\
\hline Ireland & $3(1.9)$ \\
\hline Yemen & $3(1.9)$ \\
\hline United Arab Emirates & $2(1.3)$ \\
\hline Unknown $^{\mathrm{a}}$ & $38(24.1)$ \\
\hline
\end{tabular}

$\mathrm{a}_{38}$ respondents did not respond to the question about their country of graduation.

Further analysis showed that the high-score group $(\mathrm{n}=57)$ comprised $7(12 \%)$ residents, $32(56 \%)$ fellows, and $18(32 \%)$ consultants, whereas the low-score group $(\mathrm{n}=101)$ comprised $27(26.7 \%)$ residents, $42(41.6 \%)$ fellows, and $32(31.7 \%)$ consultants (Table 2). Figure 1 shows the percentage of high and low scores across gender and different groups of physicians.
No statistically significant difference was found between the scores of respondents in the 25- to 30-year age group and those aged above 30 years. Rank of the physician (ie, residents, fellows, or consultants), year of training among residents and fellows, and country of graduation also did not have a statistically significant effect on the total scores (Table 3 ). 
Table 2. Comparison of age, gender, and designation of participants in the high-score group ( $\mathrm{n}=57)$.

\begin{tabular}{llc}
\hline Variable & Participants who scored $\geq 60 \%, \mathrm{n}(\%)$ & $P$ value \\
\hline Age (years) & & .62 \\
$25-30(\mathrm{n}=37)$ & $12(32)$ & .59 \\
$>30(\mathrm{n}=121)$ & $45(37)$ & .23 \\
Gender & $46(35)$ & $11(41)$ \\
$\quad$ Male $(\mathrm{n}=131)$ & & \\
Female $(\mathrm{n}=27)$ & $7(21)$ & $32(43)$ \\
Level of training & $18(36)$ \\
$\quad$ Residents $(\mathrm{n}=34)$ & & \\
Fellows $(\mathrm{n}=74)$ & & \\
Consultants $(\mathrm{n}=50)$ &
\end{tabular}

Figure 1. Percentages of high and low scores across gender and different groups of physicians.

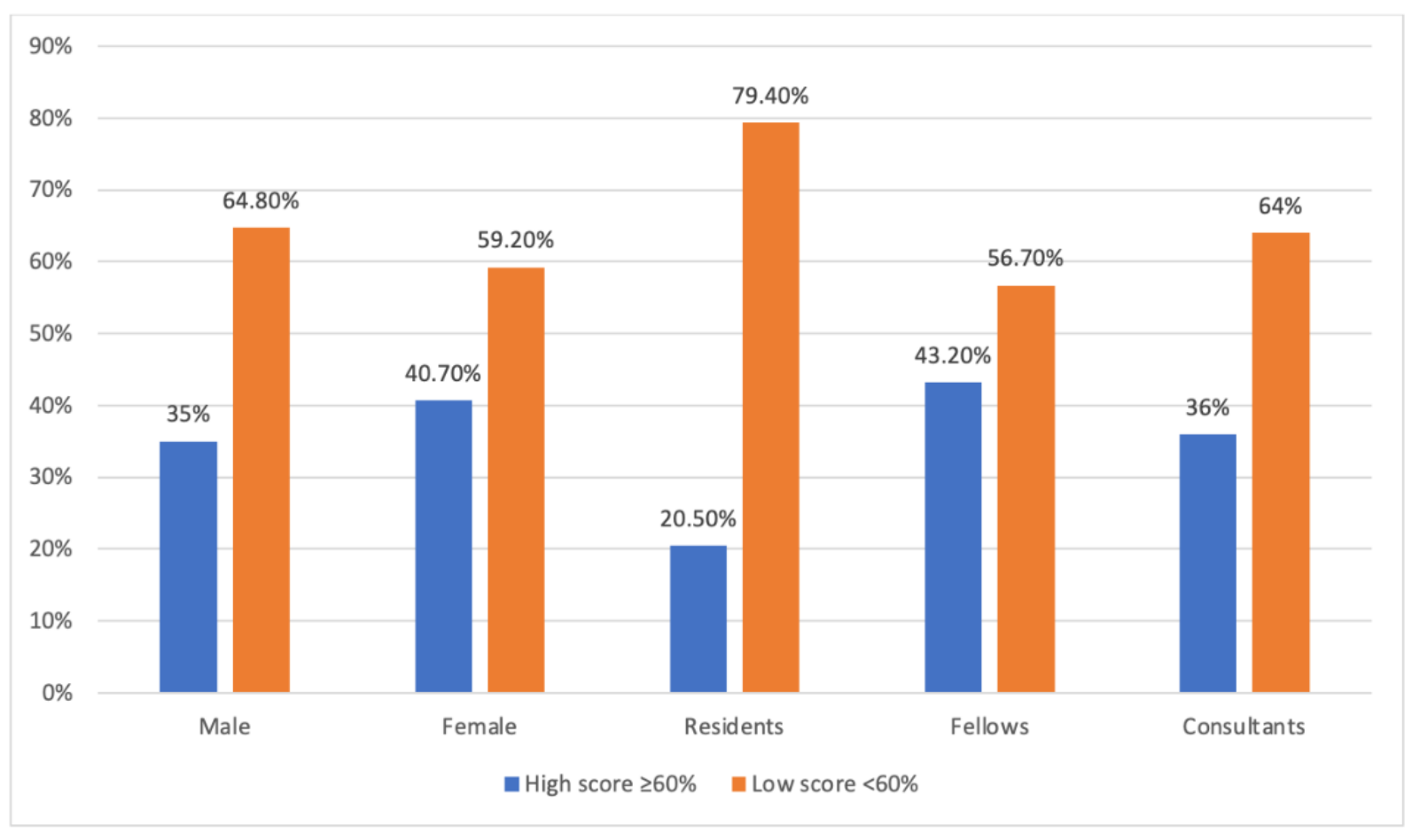


Table 3. Comparison of the years and level of training and country of graduation of participants in the high-score group (n=57).

\begin{tabular}{|c|c|c|}
\hline Variable & Participants who scored $\geq 60 \%, \mathrm{n}(\%)$ & $P$ value \\
\hline Year of training & & .84 \\
\hline \multicolumn{3}{|l|}{ Resident } \\
\hline First year $(n=10)$ & $2(20)$ & \\
\hline Second year $(n=4)$ & $2(50)$ & \\
\hline Third year $(n=16)$ & $2(13)$ & \\
\hline Fourth year $(n=4)$ & $1(25)$ & \\
\hline \multicolumn{3}{|l|}{ Fellow } \\
\hline First year $(n=15)$ & $7(47)$ & \\
\hline Second year $(n=12)$ & $6(50)$ & \\
\hline Third year $(n=16)$ & $8(50)$ & \\
\hline Fourth year $(\mathrm{n}=5)$ & $1(20)$ & \\
\hline More than 4 years $(n=26)$ & $10(38)$ & \\
\hline Country of graduation & & .63 \\
\hline Pakistan (n=25) & $10(40)$ & \\
\hline Jordan $(\mathrm{n}=16)$ & $4(25)$ & \\
\hline Libya $(n=14)$ & $3(21)$ & \\
\hline Syria $(n=12)$ & $5(42)$ & \\
\hline Sudan $(n=12)$ & $6(50)$ & \\
\hline India $(\mathrm{n}=10)$ & $5(50)$ & \\
\hline Egypt $(\mathrm{n}=8)$ & $5(63)$ & \\
\hline Qatar $(\mathrm{n}=7)$ & $3(43)$ & \\
\hline United Kingdom ( $\mathrm{n}=4)$ & $1(25)$ & \\
\hline Palestine $(n=4)$ & $2(50)$ & \\
\hline Ireland $(\mathrm{n}=3)$ & $1(33)$ & \\
\hline Yemen $(n=3)$ & $1(33)$ & \\
\hline United Arab Emirates $(\mathrm{n}=2)$ & $1(50)$ & \\
\hline Other unknown countries $^{\mathrm{a}}(\mathrm{n}=38)$ & $10(26)$ & \\
\hline
\end{tabular}

${ }^{\mathrm{a}} 10$ participants who scored $\geq 60 \%$ did not disclose their country of graduation.

\section{Discussion}

Our study shows that postgraduate medical residents, fellows, and consultants in internal medicine or subspecialties at the largest tertiary care government hospital in Qatar have average to below-average knowledge in sleep medicine. The prevalence of obesity in Qatar is quite high, with $35 \%$ of men and $45 \%$ of women having a BMI higher than 30 [11]. Prevalence of obesity and consequent sleep-related breathing disorders are constantly rising, which can be attributed to the sedentary lifestyle, decreased physical activity, and unfavorable weather conditions possibly hindering a more active lifestyle. Sleep disorders are common worldwide; however, epidemiological studies on its prevalence are lacking in the State of Qatar. Anecdotal evidence reveals that, on average, 10 new patients with sleep-related breathing disorders are diagnosed in pulmonary clinics every week. This points to a high prevalence of sleep-related breathing disorders in the country.

In our study, only $35.8 \%$ of participants correctly answered more than $60 \%$ of the questions. Our results did not differ much from the previous studies assessing sleep knowledge across different countries in the Middle East region. For instance, a study comprising 215 physicians in Turkey showed that $45.3 \%$ of them answered questions correctly on a questionnaire assessing knowledge about sleep medicine [12]. Another similar study comprising primary health care physicians, of whom $94 \%$ were board-certified and $76 \%$ were certified in more than one field, rated their knowledge of sleep medicine as fair or poor [13]. In Egypt, Zaki et al [14] assessed the knowledge of normal sleep and sleep disorders among final-year medical students and house-officers from seven different medical faculties, also using the ASKME questionnaire. They found that $91 \%$ of the 
study participants had limited knowledge of sleep disorders, which is consistent with our results.

In our study, the mean score obtained by the participants was 15.53 (ie, $51.7 \%$ ), which was significantly lower than the mean score obtained by practicing physicians $(66 \%)$ and medical students (56\%) in the United states [10]. However, physicians in our study fared better than practicing physicians in Egypt, Croatia, and Saudi Arabia [14-16]. Comparison of mean ASKME scores of participants of our study and those of studies carried out in other countries is presented in Figure 2. Similar results were reported when a different survey was used to assess sleep knowledge. For example, a cross-sectional survey of general practice physicians in Ecuador, Peru, and Venezuela, using the OSA Knowledge and Attitudes (OSAKA) questionnaire demonstrated that although $73.5 \%$ of the physicians felt confident in identifying patients at risk for OSA, only $35.4 \%$ felt confident in managing these patients [17]. Similarly, behavior, attitude, and knowledge of sleep medicine assessed using MED sleep survey among interns and medical residents in university hospitals of central India revealed that average scores were 12.6 (ie, less than 50\%). Moreover, 52.6\% of the residents and $31.15 \%$ of the interns participating in this study obtained a score of more than $50 \%$, which could be attributed to the increased exposure of residents to the medical literature [18]. Our study findings showed that trainees in fellowship programs had more knowledge in sleep than did interns and consultants, likely from increased exposure to consultations and a strong knowledge base from attending board certification residency exams.

Figure 2. Comparison of the mean Assessment of Sleep Knowledge in Medical Education (ASKME) Survey scores obtained by physicians participating in this study and those obtained by physicians and students in studies in other countries using the same assessment tool $[10,14,16,20]$.

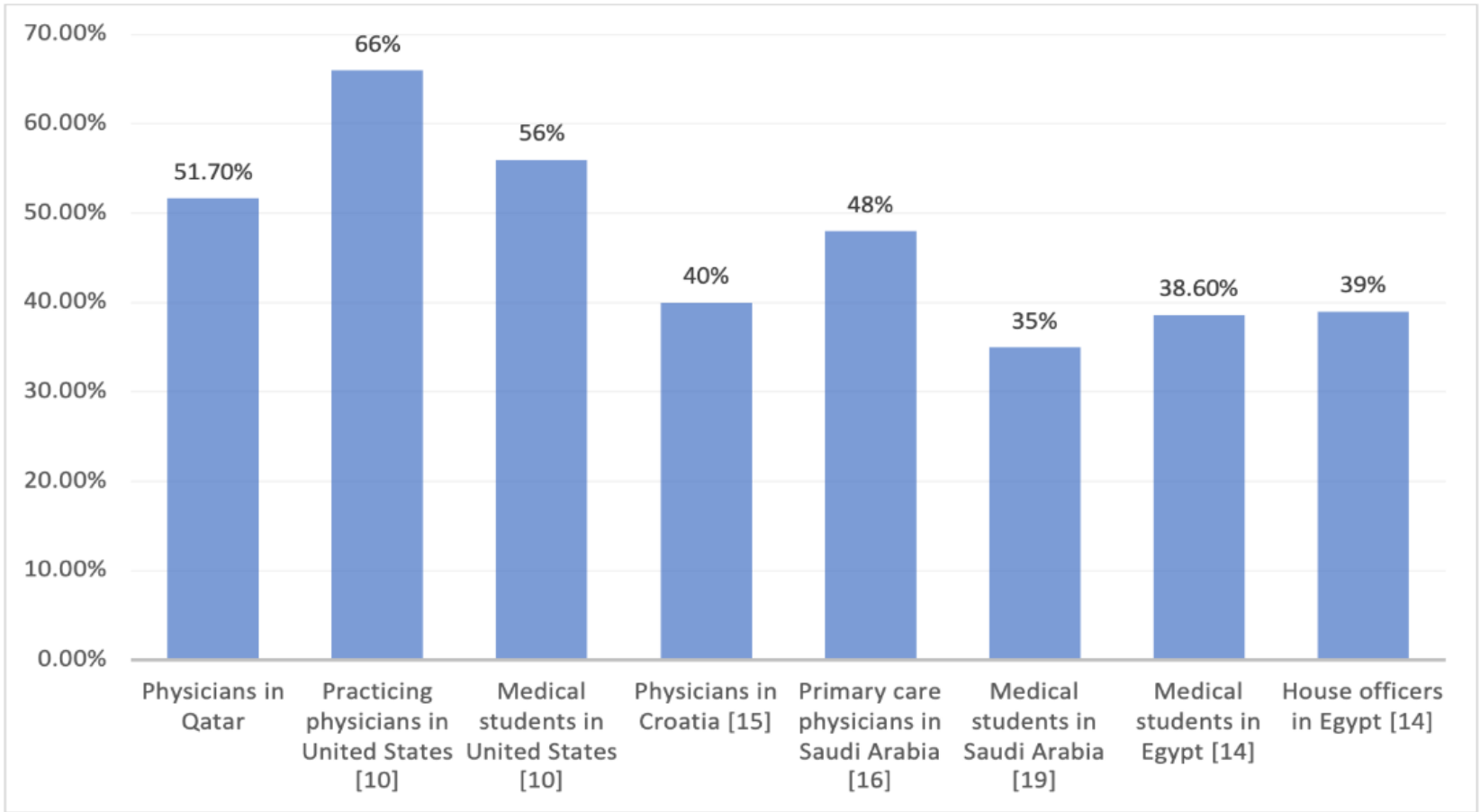

It is worth mentioning an interesting study conducted in Hyderabad, India, wherein they found that only half of the practicing chest physicians could correctly answer $50 \%$ of the questions related to sleep-disordered breathing and only $10 \%$ of the respondents could answer $75 \%$ of the questions correctly [20]. These estimates demonstrate that even respiratory physicians exhibit a poor understanding of sleep disorders. Although our target population excluded chest physicians, our study shows similar results highlighting that after completion of graduate and/or postgraduate training, physicians are likely less exposed to updates or educational activities in sleep medicine, resulting in a decrement of knowledge of sleep disorders. Based on these findings, we can infer that health care providers worldwide exhibit a poor understanding of sleep disorders.

Most of the studies have not explored the obstacles related to poor knowledge of sleep disorders among health care providers. The lack of knowledge regarding sleep medicine could be the result of the limited time assigned for teaching sleep medicine at medical schools. A study from Saudi Arabia comprising undergraduate medical students using the ASKME Survey showed that the majority of the participants recorded their sleep knowledge as below average, with no difference in the scores observed among participants of different universities, gender, or academic level [19]. The main factor identified for this level of performance was the low priority for sleep medicine in the medical curriculum and the lack of time required to implement it. In 1998, a survey by the American Sleep Disorders Association and Sleep Research Society in the United States reported similar findings, with an average of 2.1 hours devoted to sleep medicine instruction at medical school. About $79 \%$ of respondents reported spending between 0.75 and 2.0 hours on the topic, $12 \%$ reported spending between 2.5 and 4 hours, and only $9 \%$ reported being provided 6-10 hours of sleep instruction. Respondents indicated that the greatest need was more instruction time - a tall order for an already crowded curriculum [21]. The absence of any significant difference in scores based 
on the country of graduation, as found in our study, also echoes these findings, thus underlining the deficiency of focus on sleep medicine in medical curricula across countries.

In the postgraduate internal medicine residency training program at our hospital, the average number of hours focused on sleep medicine training is less than 1 hour (in the form of didactic lectures). Majority of the knowledge is gained from clinical experience and through taking various international certification exams. Although there are faculty-trained and board-certified physicians in sleep medicine who regularly conduct sleep clinics with the support of a sleep laboratory run by two certified sleep technologists, there is no structured sleep medicine training or fellowship program in Qatar yet. This could also account for the low scores obtained among the trainees in our study. A review of sleep physiology and didactic lectures on obstructive sleep apnea and other sleep disorders along with their management is provided only in the pulmonary fellowship training program. Trainees in the pulmonary fellowship have electives in a sleep laboratory to understand how sleep studies are conducted and interpreted. Furthermore, a 2007 review of medical specialty textbooks found that information on sleep and sleep disorders constituted only about $2 \%$ of the overall content [22]. This lack of emphasis has contributed to the medical culture in which few physicians, other than sleep specialists, ask questions about sleep when recording a patient's history [8]. Our survey findings highlight the need for improving training in sleep medicine among postgraduate trainees in internal medicine and subspecialties. Didactic lectures can be complemented with sleep medicine modules. Introduction of educational modules has shown that successful learning can be achieved from these modules as well, when compared to the traditional educational metric on time spent on clinical rotation [23]. Distance learning and e-learning with collaborative institutes could also serve as a platform to enhance the knowledge and attitudes in sleep medicine. It is important to develop the structural framework for clinical experience, sleep education, conduct, and interpretation of sleep studies in relevant subspecialties. This would ensure more fellows entering the field of sleep medicine.

The gap between what we know about sleep and the limited exposure to that knowledge an average trainee or consultant receives at both the undergraduate and postgraduate levels highlights the need for more instruction time devoted to this topic. At the undergraduate level, integrating information on sleep and sleep disorders into the existing medical school curriculum could help, whereas at the postgraduate level, introduction of sleep modules and structured sleep medicine training programs may enhance knowledge of screening, diagnosis, and treatment of sleep disorders.

\section{Conclusions}

Physicians working at Hamad Medical Corporation, Qatar, exhibit poor knowledge of sleep medicine, which could be attributed to the weak level of education in this field of medicine. Sleep disorders constitute a significant health problem and, if detected early, can generally be treated, improving the health and quality of life for these patients. Therefore, its necessary to emphasize on sleep medicine and sleep disorders during medical school education and residency training.

\section{Acknowledgments}

The authors gratefully acknowledge Dr Hisham Abdul Aleem Abdul Sattar for his support and encouragement throughout this research project.

\section{Authors' Contributions}

IUH and MAH conceptualized the study. IUH, KSS, and SA obtained the data. MA and AAA assisted with data collection and interpretation. Funds were collected by SA and AAA. MMT, MAH, and AMMO performed data analysis and created all tables. MMT, MAH, and IUH wrote the manuscript with input from all the authors.

\section{Conflicts of Interest}

None declared.

\section{References}

1. Brown CA, Wielandt P, Wilson D, Jones A, Crick K. Healthcare providers' knowledge of disordered sleep, sleep assessment tools, and nonpharmacological sleep interventions for persons living with dementia: a national survey. Sleep Disord 2014;2014:286274 [FREE Full text] [doi: 10.1155/2014/286274] [Medline: 24851185]

2. Jennum P, Kjellberg J. Health, social and economical consequences of sleep-disordered breathing: a controlled national study. Thorax 2011 Jul;66(7):560-566. [doi: 10.1136/thx.2010.143958] [Medline: 21199816]

3. Laaban J, Mounier L, Roque d'Orbcastel O, Veale D, Blacher J, Melloni B, ANTADIR Working group "CV risk in OSAS", CMTS, ANTADIR. Cardiovascular risk factors in men and women with obstructive sleep apnoea syndrome. Respir Med 2010 Jul;104(7):1063-1068 [FREE Full text] [doi: 10.1016/j.rmed.2010.02.021] [Medline: 20303248]

4. Punjabi NM, Caffo BS, Goodwin JL, Gottlieb DJ, Newman AB, O'Connor GT, et al. Sleep-disordered breathing and mortality: a prospective cohort study. PLoS Med 2009 Aug;6(8):e1000132 [FREE Full text] [doi:

10.1371/journal.pmed.1000132] [Medline: 19688045]

5. Jennum P, Riha RL. Epidemiology of sleep apnoea/hypopnoea syndrome and sleep-disordered breathing. Eur Respir J 2009 Apr;33(4):907-914 [FREE Full text] [doi: 10.1183/09031936.00180108] [Medline: 19336593] 
6. Wali SO, Abalkhail B, Krayem A. Prevalence and risk factors of obstructive sleep apnea syndrome in a Saudi Arabian population. Ann Thorac Med 2017;12(2):88-94 [FREE Full text] [doi: 10.4103/1817-1737.203746] [Medline: 28469718]

7. Cappuccio F, Miller M, Lockley S. eds. Sleep, Health and Society: From Aetiology to Public Health. Oxford University Press; 2010.

8. 2005 Sleep in America Poll - Summary of Findings. National Sleep Foundation. Washington, DC: National Sleep Foundation; 2005. URL: https://www.sleepfoundation.org/wp-content/uploads/2018/10/2005 summary of findings.pdf?x62386 [accessed 2020-10-20]

9. Young T, Peppard PE, Gottlieb DJ. Epidemiology of obstructive sleep apnea: a population health perspective. Am J Respir

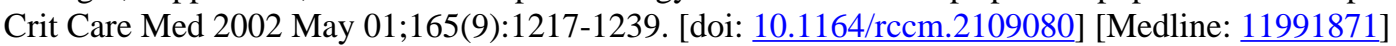

10. Zozula R, Bodow M, Yatcilla D, Cody R, Rosen RC. Development of a brief, self-administered instrument for assessing sleep knowledge in medical education: "the ASKME Survey". Sleep 2001 Mar 15;24(2):227-233. [Medline: 11247060]

11. Ng SW, Zaghloul S, Ali HI, Harrison G, Popkin BM. The prevalence and trends of overweight, obesity and nutrition-related non-communicable diseases in the Arabian Gulf States. Obes Rev 2011 Jan;12(1):1-13. [doi: 10.1111/j.1467-789X.2010.00750.x] [Medline: 20546144]

12. Gelir E, Ardiç S, Izci B. A questionnaire survey among Turkish physicians about sleep disorders. Tuberk Toraks 2004;52(4):348-355. [Medline: 15558357]

13. Papp KK, Penrod CE, Strohl KP. Knowledge and attitudes of primary care physicians toward sleep and sleep disorders. Sleep Breath 2002 Sep;6(3):103-109. [doi: 10.1007/s11325-002-0103-3] [Medline: 12244489]

14. FW Zaki N, Marzouk R. Sleep medicine knowledge among medical students in seven Egyptian medical faculties. J Sleep Disord Ther 2016;05(02):239. [doi: 10.4172/2167-0277.1000239]

15. Kovacić Z, Marendić M, Soljić M, Pecotić R, Kardum G, Dogas Z. Knowledge and attitude regarding sleep medicine of medical students and physicians in Split, Croatia. Croat Med J 2002 Feb;43(1):71-74 [FREE Full text] [Medline: 11828565]

16. Saleem AH, Al Rashed FA, Alkharboush GA, Almazyed OM, Olaish AH, Almeneessier AS, et al. Primary care physicians' knowledge of sleep medicine and barriers to transfer of patients with sleep disorders. A cross-sectional study. Saudi Med J 2017 May;38(5):553-559 [FREE Full text] [doi: 10.15537/smj.2017.5.17936] [Medline: 28439609]

17. Cherrez Ojeda I, Jeffe DB, Guerrero T, Mantilla R, Santoro I, Gabino G, et al. Attitudes and knowledge about obstructive sleep apnea among Latin American primary care physicians. Sleep Med 2013 Oct;14(10):973-977. [doi:

10.1016/j.sleep.2013.06.005] [Medline: 23973417]

18. Meshram S, Meshram C, Mishra G, Bharshankar R. Behavior, attitude and knowledge of sleep medicine among resident doctors in university hospitals of Central India: A questionnaire based study. Indian Sleep Med 2007;258(4):139-144. [doi: 10.5005/ijsm-2-4-139]

19. Almohaya A, Qrmli A, Almagal N, Alamri K, Bahammam S, Al-Enizi M, et al. Sleep medicine education and knowledge among medical students in selected Saudi Medical Schools. BMC Med Educ 2013 Sep 27;13:133 [FREE Full text] [doi: 10.1186/1472-6920-13-133] [Medline: 24070217]

20. Vigg A, Vigg A, Vigg A. Awareness of issues related to sleep disordered breathing amongst practicing physicians. Indian J Chest Dis Allied Sci 2005;47(1):25-29. [Medline: 15704712]

21. Rosen R, Mahowald M, Chesson A, Doghramji K, Goldberg R, Moline M, et al. The Taskforce 2000 survey on medical education in sleep and sleep disorders. Sleep 1998 May 01;21(3):235-238. [doi: 10.1093/sleep/21.3.235] [Medline: 9595601]

22. Teodorescu MC, Avidan AY, Teodorescu M, Harrington JJ, Artar AO, Davies CR, et al. Sleep medicine content of major medical textbooks continues to be underrepresented. Sleep Med 2007 Apr;8(3):271-276. [doi: 10.1016/j.sleep.2006.09.001] [Medline: 17369089]

23. Avidan AY, Vaughn BV, Silber MH. The current state of sleep medicine education in US neurology residency training programs: where do we go from here? J Clin Sleep Med 2013 Mar 15;9(3):281-286 [FREE Full text] [doi: 10.5664/jcsm.2502] [Medline: 23493388]

\section{Abbreviations}

ACGME-I: The Accreditation Council for Graduate Medical Education-International

ASKME: Assessment of Sleep Knowledge in Medical Education

EDS: excessive daytime sleepiness

OSA: obstructive sleep apnea

OSAKA: Obstructive Sleep Apnea Knowledge and Attitudes 
Edited by G Eysenbach; submitted 09.11.20; peer-reviewed by W Safi, C Stepnowsky; comments to author 30.12.20; revised version received 23.02.21; accepted 14.04.21; published 12.05.21

Please cite as:

Haq IU, Hameed MA, Thomas MM, Syed KS, Othman AMM, Ahmed S, Alabbas AA, Ahmad M

Knowledge of Sleep Disorders Among Physicians at a Tertiary Care Hospital in Qatar: Cross-sectional Study

Interact J Med Res 2021;10(2):e25606

URL: https://www.i-jmr.org/2021/2/e25606

doi: $10.2196 / 25606$

PMID:

(CIrfan Ul Haq, Mansoor Ali Hameed, Merlin Marry Thomas, Khezar Shahzada Syed, Ahmad Mohammad Mahmoud Othman, Shakeel Ahmed, Abbas Abdallah Alabbas, Mushtaq Ahmad. Originally published in the Interactive Journal of Medical Research (https://www.i-jmr.org/), 12.05.2021. This is an open-access article distributed under the terms of the Creative Commons Attribution License (https://creativecommons.org/licenses/by/4.0/), which permits unrestricted use, distribution, and reproduction in any medium, provided the original work, first published in the Interactive Journal of Medical Research, is properly cited. The complete bibliographic information, a link to the original publication on https://www.i-jmr.org/, as well as this copyright and license information must be included. 